\title{
Influence of biopolymer gel-coated fibres on sand reinforcement as a model of plant root behaviour
}

\author{
Chunhui Chen $\cdot \mathrm{Li} \mathrm{Wu} \cdot$ Michael Harbottle $\mathbb{D}$
}

Received: 13 November 2018 / Accepted: 12 March 2019/Published online: 18 March 2019

(C) The Author(s) 2019

\begin{abstract}
Aims The contribution of plant mucilage and microbial biofilms in the rhizosphere to the physical behaviour of roots, and therefore on geotechnical performance, is not fully understood. We explore the impact of biopolymers on the ability of fibrous inclusions in soil to resist shear loading, to test the hypothesis that biopolymerenhanced cohesion will be most significant at shallow depths where frictional effects are less, whilst exploring the response of biopolymer to changes in the moisture regime.

Methods Artificial root/biopolymer systems comprising 3D-printed fibres and xanthan gum biopolymer in sand have been tested under direct shear at low vertical normal stress (1-30 kPa). The impact of drying and wetting on the ability of the reinforced sand to resist shear was assessed.
\end{abstract}

Responsible Editor: Zhun Mao.

C. Chen $\cdot$ L. Wu

Faculty of Engineering, China University of Geosciences Wuhan, No. 388 Lumo Road, Wuhan 430074, People's Republic of China

C. Chen

e-mail: cchmike@hotmail.com

L. $\mathrm{Wu}$

e-mail: lwu@cug.edu.cn

C. Chen $\cdot$ M. Harbottle $(\square)$

Cardiff School of Engineering, Cardiff University, Queen's

Buildings, The Parade, Cardiff, Wales CF24 3AA, UK

e-mail: harbottlem@cardiff.ac.uk
Results Fibres combined with fresh biopolymer caused an increase in mobilisable shear stress, which is proportionally more significant at lower normal stress and so shallower depth (up to $30 \%$ increase at $1 \mathrm{kPa}$ ). Increased shear resistance and sand aggregation were observed with progressive drying. A cyclic shear response was observed over wetting and drying cycles with considerable strengthening after drying, which was enhanced by preceding wetting increasing the biopolymer zone of influence around the fibre.

Conclusions The behaviour of this idealised system attests that root-associated biopolymers contribute significantly to the stabilisation of shallow soil by creating bonds between the root and soil grains, but the response is dependent on the soil moisture regime.

Keywords Root-soil interaction · Mucilage . Biopolymer Fibre reinforcement

\section{Introduction}

The contribution of vegetation to the mechanical and hydraulic performance of soils is well-known. In particular, the compressive stresses acting in a soil cause frictional interaction and interlocking between the root and soil grains. If two soil regions connected by a root are sheared relative to one another during deformation, a fine, flexible root will go into tension whilst a rigid, woody root would be able to sustain a degree of shear as well as tension (depending on orientation), resisting this movement (Stokes et al. 2009). This understanding has 
contributed to the development of fibre-reinforced soils, which employ artificial or natural fibres as a soil additive (Hejazi et al. 2012). The second major component of root-enhanced geotechnical performance is changes to the hydrogeological regime via evapotranspiration. Removal of water from the soil can increase matric suction leading to increased effective stress and consequently increased ability of a soil to resist deformation due to loading (Vanapalli et al. 1996). The extent of this effect is complex, and is partially dependent on the degree of evapotranspiration, which varies across seasons and partially on the depth of any failure zone (Kim et al. 2017; Ni et al. 2018; Stokes et al. 2009).

Plants in soil comprise a complex ecosystem (Danjon and Reubens 2008) and form a composite which is far more complicated than simply fibre-reinforced materials. In particular, plants and associated microorganisms secrete a range of organic materials which impact upon soil behaviour. Root exudates are a heterogeneous mix of various chemicals with purposes including root tip lubrication and mobilisation of desirable chemical species for plant uptake (Jones et al. 2009; Walker et al. 2003). It has become apparent that mucilage alters soil structure in the zone immediately surrounding the root (Carminati et al. 2016), changing both the mechanical and hydrological behaviour of this zone to the benefit of the plant. Microorganisms, stimulated and supported through the high levels of bioavailable plant secretions in the rhizosphere, themselves exude primarily carbohydrate-based polymeric substances resulting in the formation of complex multi-species communities encapsulated within biopolymer matrices, known as biofilms (Hall-Stoodley et al. 2004). These combined biopolymers (mucigel) allow greater moisture retention in the rhizosphere for a given negative water potential (Kroener et al. 2014) and are slow to both release water under drying conditions and to absorb water under wetting conditions, buffering and smoothing the impacts of wetting and drying cycles whilst maintaining moisture availability for the plant (Carminati et al. 2010; Zickenrott et al. 2016). Mechanical adhesion of soil grains to roots, facilitated by the mucigel, helps to encourage contact between the root and soil, particularly during dry conditions, and facilitates water flow into root hairs at more negative water potentials and so allows better capture as well as retention of moisture (Carminati et al. 2016).

Both plant and microbial biopolymers are known to impact mechanical soil properties. Biofilms have been shown to improve the peak shear strength of sands (Ahmed and Hussain 2010; Banagan et al. 2010) under certain conditions. Fresh root exudate has been shown to decrease penetration resistance allowing root elongation (Oleghe et al. 2017). It causes adhesion of soil grains to roots (Gregory 2006), as well as encourage aggregation of soil grains in proximity to the rhizosphere (Carminati et al. 2016; DeJong et al. 2010; Hinsinger et al. 2009), effectively anchoring the plant to the surrounding soil (Di Marsico et al. 2018; Whalley et al. 2005). The movement of a root relative to the soil during deformation will therefore take adhered grains with it, effectively increasing the diameter of the root and increasing the area of the shear plane between soil and root, which is expected to impact upon the resistance to movement of plant roots through the soil (Hinsinger et al. 2009). Bond strengths between soil grains and soil and root surfaces are enhanced with wetting and drying cycles, as upon drying mucilage polymers are concentrated in bridges between surfaces which are resilient to disruption by subsequent wetting (Albalasmeh and Ghezzehei 2014; Benard et al. 2018). Mucilage can, however, vary in its ability to stabilise soils in this way, with the polysaccharide content found to be an important determinant of stabilisation ability (Naveed et al. 2017a, b). Model biopolymer models using plant and microbial exudates have been employed to explore the nature of the soil/root/mucigel relationship including polygalacturonic acid (PGA) as a model mucilage (Albalasmeh and Ghezzehei 2014; Czarnes et al. 2000; Peng et al. 2011), and dextran and xanthan gum as model microbial exudates (Czarnes et al. 2000; Peng et al. 2011). Both PGA and xanthan gum were found to have substantial effects on soil tensile strength and aggregation, and both offered some resilience to porosity changes upon wetting and drying cycles although the former impacted water repellency to a greater degree and offered a greater resilience (Czarnes et al. 2000). Peng et al. (2011) found comparable effects although xanthan gum had the greatest impact on tensile strength whilst PGA was ineffective although the latter was tentatively attributed to the relatively large experimental sample size. In addition, artificial biopolymers have also demonstrated a considerable ground improvement effect when added in large amounts (Chang et al. 2016). Based on the above understanding of the effects of plant and microbial biopolymers on the rhizosphere, the formation of a coherent rhizosheath around a root and changes to the geomechanical properties of the surrounding soil, such as increased aggregation, may be 
expected to contribute to the ability of plants to enhance geotechnical performance. However, the extent of this is currently unknown.

Whilst the effect of root-associated biopolymers on soil aggregation and related behaviour is well-known, the subsequent impact of these materials on the engineering behaviour of a particulate medium has received less attention. The purpose of this study was, therefore, to explore the contribution of root-associated biopolymers to the geotechnical performance of rooted soils. We test the hypothesis that additional cohesion imparted by biopolymers will have influence at low normal stresses experienced at shallow depths but that this influence will wane with depth as frictional behaviour dominates the soil shear performance. An experimental analogue of vegetated soil was employed, with xanthan gum gel-coated fibres as a mimic of roots and associated mucilage and biofilm. The natural root-soil relationship is complex and so by exploring an idealised scenario with appropriate control over testing parameters we are able to elucidate the effects of fibre content, root depth, xanthan gum gel concentration (i.e. viscosity) and impact of wetting and drying cycles.

\section{Materials and methods}

Soil size and properties

A fine to medium well graded silica sand (coefficient of uniformity $\left[C_{u}\right]-2.41$; coefficient of gradation $\left[C_{g}\right]-$ 1.28 ) with a specific gravity of 2.65 was employed.

Fibres

Branched fibres are considered here as idealised models of individual roots. In order to produce sufficient numbers of fibres to mimic typical fibre area ratios, 3D printing of polylactic acid (PLA) was employed. Each fibre had a main stem $30 \mathrm{~mm}$ in length with a cylindrical cross-section $1 \mathrm{~mm}$ in diameter with six $3 \mathrm{~mm}$ long branches evenly spaced either side of the main stem, as shown in Fig. 1. The tensile strength of plant roots typically ranges from $5 \mathrm{MPa}$ to $100 \mathrm{MPa}$ (De Baets et al. 2008), while here the tensile strength of the artificial fibre was determined to be $25 \mathrm{MPa}$ indicating that the fibres are representative of roots in this regard.

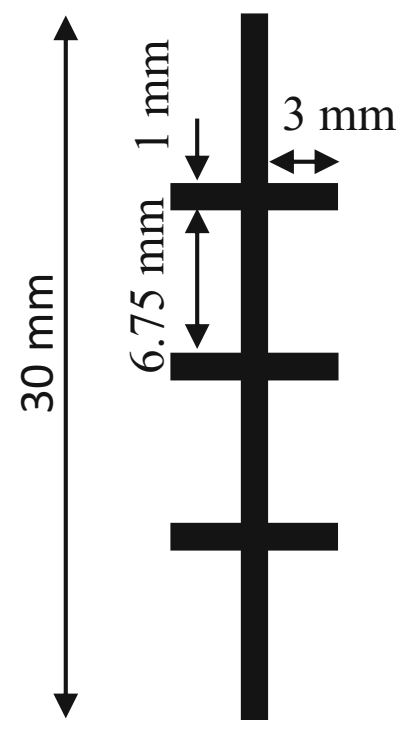

Fig. 1 Schematic of branched fibre shape and dimensions

Xanthan gum

Xanthan gum is a polysaccharide secreted by the bacterium Xanthomonas campestris, used commercially as a food additive and rheology modifier. It dissolves in water but is viscous at low concentrations, with decreasing viscosity at higher shear stress. It is used here to mimic plant mucilage and microbial biopolymers typically present in soil. Previous studies have found it to be an acceptable physical model of the primarily polysaccharide-based exopolymeric substances that comprise biofilms (Czarnes et al. 2000; Malarkey et al. 2015) and plant mucilage (Di Marsico et al. 2018), with mucilages being considered as alternatives for commercial products such as xanthan gum. It has also been demonstrated to have significant soil adhesion properties, comparable to those of plant-exuded gums (Akhtar et al. 2018) whilst its effect on the mechanical properties of the soil has been found to have similarities to those of a common mucilage model, polygalacturonic acid (Czarnes et al. 2000).

\section{Sample preparation}

Xanthan gum gel was prepared by mixing xanthan gum powder $(2 \%$ or $4 \% \mathrm{w} / \mathrm{v})$ into distilled water using a magnetic stirrer for $30 \mathrm{~min}$. The gel was then manually applied to the fibres where appropriate by using tweezers to place fibres in the gel. Fibres were then weighed to check consistency of gel addition. The typical mass of 
gel attached per batch of 24 fibres was $3.6 \mathrm{~g}$ for $2 \% \mathrm{w} / \mathrm{v}$ gel, and $4.0 \mathrm{~g}$ for $4 \% \mathrm{w} / \mathrm{v}$ gel $(0.15$ and $0.2 \mathrm{~g}$ per fibre respectively). Such gel concentrations are higher than those sometimes used to model biopolymers (e.g. Peng et al. (2011)) but were necessary to allow adhesion of an appropriate amount of gel to the fibres. Because the moisture levels within an exuded gel will equilibrate with the surrounding soil environment, the concentration of a biopolymer gel in the rhizosphere may take a range of values over time and so a range of values, including those used here, may be representative of conditions at different times.

Direct shear tests were carried out in standard shear box apparatus $(60 \times 60 \mathrm{~mm}$ specimens in plan, $45 \mathrm{~mm}$ depth). These dimensions are smaller than those typically used in physical and numerical modelling of rooted soil specimens (e.g. Sadek et al. (2010), Mao et al. (2014)), where large apparatus is used due to the potential variability of root systems and the need to encompass a representative specimen. Conversely, in this study we employ a regular and repeatable artificial fibre structure (similar to Gray and Ohashi (1983) who used apparatus of similar dimensions) - with consistent fibre dimensions and arrangements, there is less need for large apparatus. Cerato and Lutenegger (2006) discuss scale effects on sand under direct shear and show that mechanical behaviour is impacted by a combination of shear box dimensions, grain size and density. However, they confirm the effect noted by Jewell and Wroth (1987) that there is little effect of scale on shear behaviour if the ratio of box width $W$ to maximum grain size $D_{\max }$ is greater than 50 as is the case in this study ( $W=$ $60 \mathrm{~mm} ; D_{\max }=1.18 \mathrm{~mm} ; W / D_{\max }=50.8$ ). Based on the above, the dimensions chosen here are considered to be appropriate for the purpose of our work.

Low normal stresses were employed and so care was taken in preparation of shear box specimens. Dry sand was employed to eliminate the effects of suction on mechanical performance. Initially, $50 \mathrm{~g}$ of sand was poured slowly into the shear box through a funnel which was supported by a frame, giving the funnel two degrees of freedom of movement but ensuring the height remained constant. The funnel was moved at a constant rate of $6 \mathrm{~cm} / \mathrm{s}$ from side to side as the funnel was moved from one end of the shear box to the other, ensuring a reasonably uniform coverage of sand. The specimen was then placed on a shaking table at $480 \mathrm{rpm}$ for one minute. Gel-coated fibres were placed vertically through a grid to ensure uniform distribution in every sample.
Fibre area ratios $\left(\mathrm{A}_{\text {fibre }} / \mathrm{A}_{\text {soil }}\right)$ of $0.26 \%$ or $0.52 \%$ (12 or 24 fibres) were employed, which correspond to typical measured root area ratios in the upper $0.5 \mathrm{~m}$ of forested slopes (Bischetti et al. 2005). Branched fibres were placed with the stem arranged vertically and the branches arranged in a plane perpendicular to the direction of movement of the shear box. A further $150 \mathrm{~g}$ sand was then placed in the shear box and shaken in the same manner as that described above. The dry densities produced by this method ranged from $1.58 \mathrm{~g} / \mathrm{cm}^{3}$ to 1. $62 \mathrm{~g} / \mathrm{cm}^{3}$. The dry biopolymer contents are $0.18 \mathrm{mg}$ and $0.36 \mathrm{mg}$ per $\mathrm{g}$ dry soil $(0.26$ and $0.52 \%$ fibre area ratios respectively) with $2 \%$ gel, and $0.48 \mathrm{mg}$ and $0.96 \mathrm{mg}$ per g dry soil with $4 \%$ gel. These are within the reasonable range of mucilage contents determined for real vegetated soils of $0.05-50 \mathrm{mg}$ per $\mathrm{g}$ dry soil (Zickenrott et al. 2016).

\section{Direct shear tests}

Direct shear tests were carried out following the British Standard method (BS 1377-7: 1990) using multiple shear box apparatuses constructed from rigid Acetal plastic. The shear boxes were machined from single blocks with no fixings or adhesives used in their production and are used for low normal stress applications only. A total of 135 tests were performed, with all tests performed on a Wykeham Farrance Direct Shear Testing apparatus, with normal stress applied using a hanger system apart from at very low stress $(1 \mathrm{kPa})$ where the weight of the top cap was sufficient. The testing rate was $0.8 \mathrm{~mm} / \mathrm{min}$. Three replicates were performed for every test scenario to assess experimental variability.

\section{Experimental structure}

\section{Effect of branched fibres}

A series of direct shear tests under low normal stress $(1 \mathrm{kPa}, 10 \mathrm{kPa}$ and $30 \mathrm{kPa}$ ) were carried out with sand only and with branched fibres $(0.26$ and $0.52 \%$ fibre area ratio).

\section{Impact of gel on fibre reinforcement of sand}

In order to mimic how plant roots and associated mucilage perform in soil stabilisation, the ability of gelcoated, branched fibres $(0.26 \%$ fibre area ratio $)$ to 
amend the shear properties of sand was explored. The effect of gel viscosity was determined by comparing the effect of gels with powder contents of 2 and $4 \%$ by mass to the effect of branched fibres in sand, and sand only (tests performed as part of the previous experiment). Each condition was again tested at normal stresses of 1,10 and $30 \mathrm{kPa}$. As above, all tests were carried out in triplicate.

\section{Effect of gel on sand structure with changing moisture conditions}

Drying of biopolymer gels will increase interaction between individual polymer molecules, increasing intermolecular bonding and increasing viscosity. This would be expected to increase sand adhesion to fibres, as well as encourage aggregation of sand particles close to the fibres. Gel-coated fibre-reinforced sand samples (2\% gel powder content; $0.26 \%$ fibre area ratio) were subjected to drying at room temperature to obtain triplicate specimens with moisture losses in the gel of 20, 40, 60, 80 and $100 \%$ (determined by mass loss of specimens) prior to testing under direct shear at a normal stress of $1 \mathrm{kPa}$. Testing was only carried out at this lowest normal stress in order to explore the impact of the presence of gel in shallow soils.

Following these tests, the degree of soil aggregation was measured by removing the fibres and any strongly adhered sand before sieving the remaining sand (in each case, all three replicates were combined into one large sample) into six fractions $(<0.063,0.063-0.15,0.15$ $0.3,0.3-0.6,0.6-1.18,>1.18 \mathrm{~mm}$ ) before measuring the mass of each fraction.

\section{Effect of wetting and drying cycles on fibre/gel/sand composites}

Specimens prepared as above ( $2 \%$ gel powder content; $0.26 \%$ branched fibre area ratio) were subjected to a number of wetting and drying cycles, with each cycle comprising immersion in distilled water for $10 \mathrm{~min}$ then complete drying at $40{ }^{\circ} \mathrm{C}$ for $96 \mathrm{~h}$ (until sample weight was constant). Drying at this temperature for relatively short periods allowed complete drying whilst minimising degradation of the biopolymer (Czarnes et al. 2000). Samples were then cooled at room temperature prior to subsequent wetting-drying cycles. Direct shear testing at a normal stress of $1 \mathrm{kPa}$ was carried out on specimens after the wetting and drying stages of 0,1 ,
2, 5 and 10 cycles. Fibre/sand (i.e. without gel) and sand-only controls were subjected to the same conditions and tested in an identical manner.

\section{Statistical analysis}

All experiments were performed in triplicate. The significance of differences between treatments was calculated using analysis of variance (Minitab v.17) with significance evaluated at $P<0.05$ level. Pairwise comparisons were made using the Tukey method at the $95 \%$ confidence level where necessary in order to determine the significance of differences between means. Summary data are presented as means and standard error of the mean $(n=3)$.

\section{Results}

\section{Effect of fibre content}

Figure 2 presents the effect of branched fibres on shear performance of sand. All replicates are presented, indicating good repeatability under all loads and conditions. Stress-strain plots are presented rather than peak versus normal stress as the behaviour varied between treatments with only some specimen groups exhibiting a peak strength. Sand-only direct shear tests were carried out as control experiments, and display a well-defined peak, and a consistent post-peak reduction and ultimate stress. Fibres with $0.52 \%$ fibre area ratio increased the maximum stress by around 20-30\%, although at a higher strain and with little or no observable post-peak reduction. At a lower fibre area ratio of $0.26 \%$, fibres had little strength improvement over sand only, and again did not exhibit a distinct peak. All fibre tests demonstrated an elevated ultimate stress compared to sand alone $(20-40 \%$ increase with $0.26 \%$ fibre area ratio, $40-50 \%$ increase with $0.52 \%$ fibre area ratio).

Xanthan gum gel as a model root mucilage - impact on shear performance of fibre-reinforced sand

Xanthan gum gel was applied as a coating to branched fibres to explore how biopolymers such as mucilage around fibrous inclusions such as roots influence soil mechanical performance. Figure 3 shows that the presence of fresh, well-hydrated xanthan gum tended to 
Fig. 2 Influence of fibre content and shape on shear behaviour of dry sand (samples tested in triplicate). Labels on right hand side indicate the normal stress applied during direct shear testing

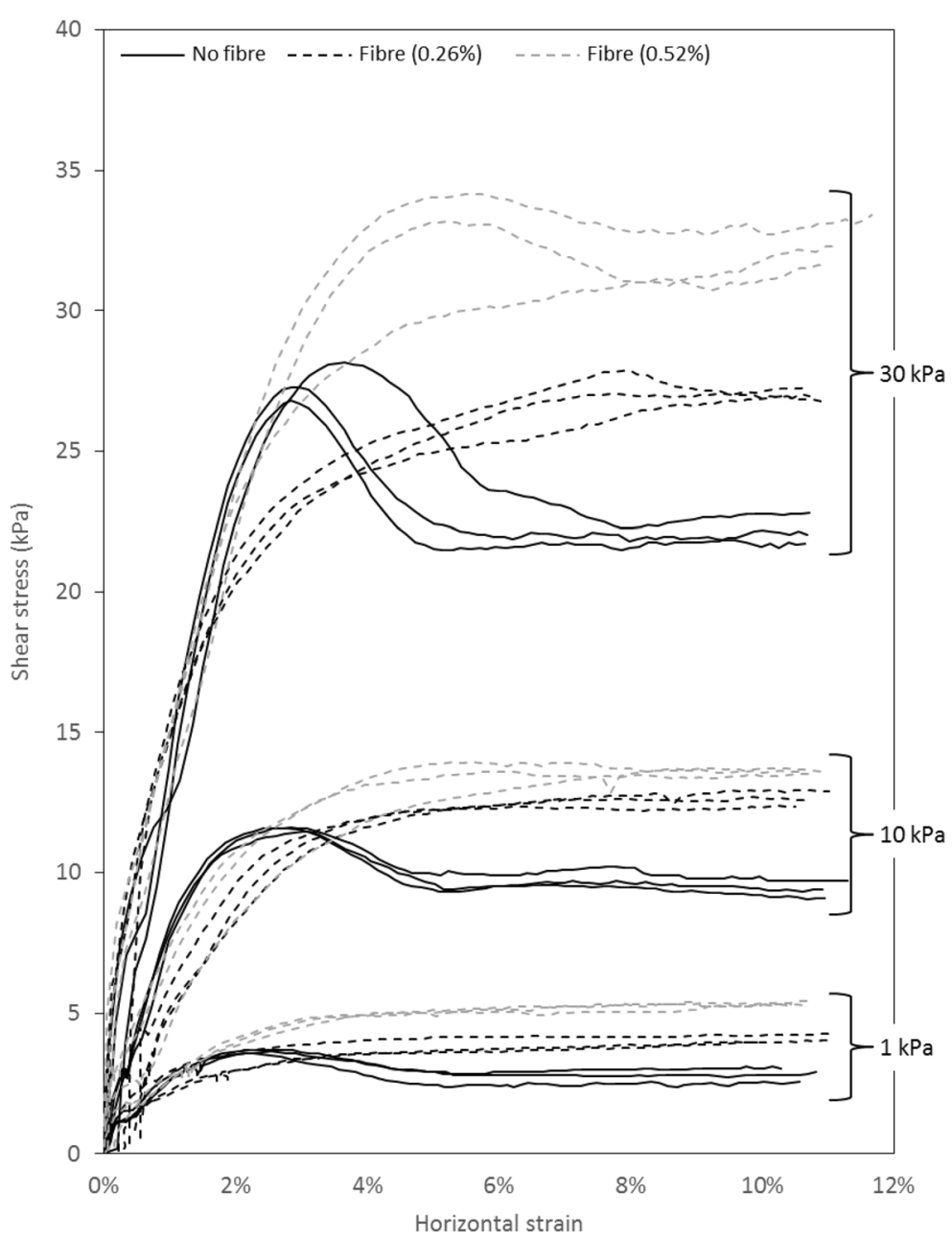

increase the maximum mobilisable shear stress in fibrereinforced sand compared to specimens reinforced with dry branched fibres only, particularly with the lower gel composition. At the highest normal stress $(30 \mathrm{kPa})$, the ultimate shear strength had not yet been reached by the end of testing. It is higher than that without gel, although is only mobilised at very high strain as the gel causes a much slower mobilisation of shear stress with increasing strain at this higher stress. The greatest proportional improvement in ultimate stress was observed at the lowest normal stress of $1 \mathrm{kPa}$ (approximately 20\%), although only slightly lesser increases may occur at $30 \mathrm{kPa}$ (determined by extrapolation of the curves).

A slightly smaller stiffness was observed with a gel concentration of $4 \%$ (Fig. 3), particularly at lower normal stresses (1 and $10 \mathrm{kPa}$ ) which may be attributed to the greater mass of gel attached to the fibre during preparation (typically $0.2 \mathrm{~g}$ per fibre, compared to $0.15 \mathrm{~g}$ per fibre with $2 \%$ gel). Although this higher concentration gel is more viscous, it is suggested that this less fluid gel is better able to resist compressive stresses forcing sand grains toward the fibre, and so better reduce the friction between the two when these compressive stresses are smaller.

A summary table containing key comparative data from Figs. 2 and 3 is presented (Table 1). Maximum stresses are presented rather than peak stresses as a number of tests did not exhibit a clear peak. In some cases, therefore, the maximum value is equivalent to the ultimate stress. Ultimate stresses were determined as either the consistent stable stress reached by the end of testing or from an average of the final five stress measurements in cases where no consistent final stress was reached (these latter cases are denoted in the table). 
Fig. 3 Influence of presence of biopolymer gel on shear behaviour of dry sand reinforced with branched fibres $(0.26 \%$ area ratio). Labels on right hand side indicate the normal stress applied during direct shear testing

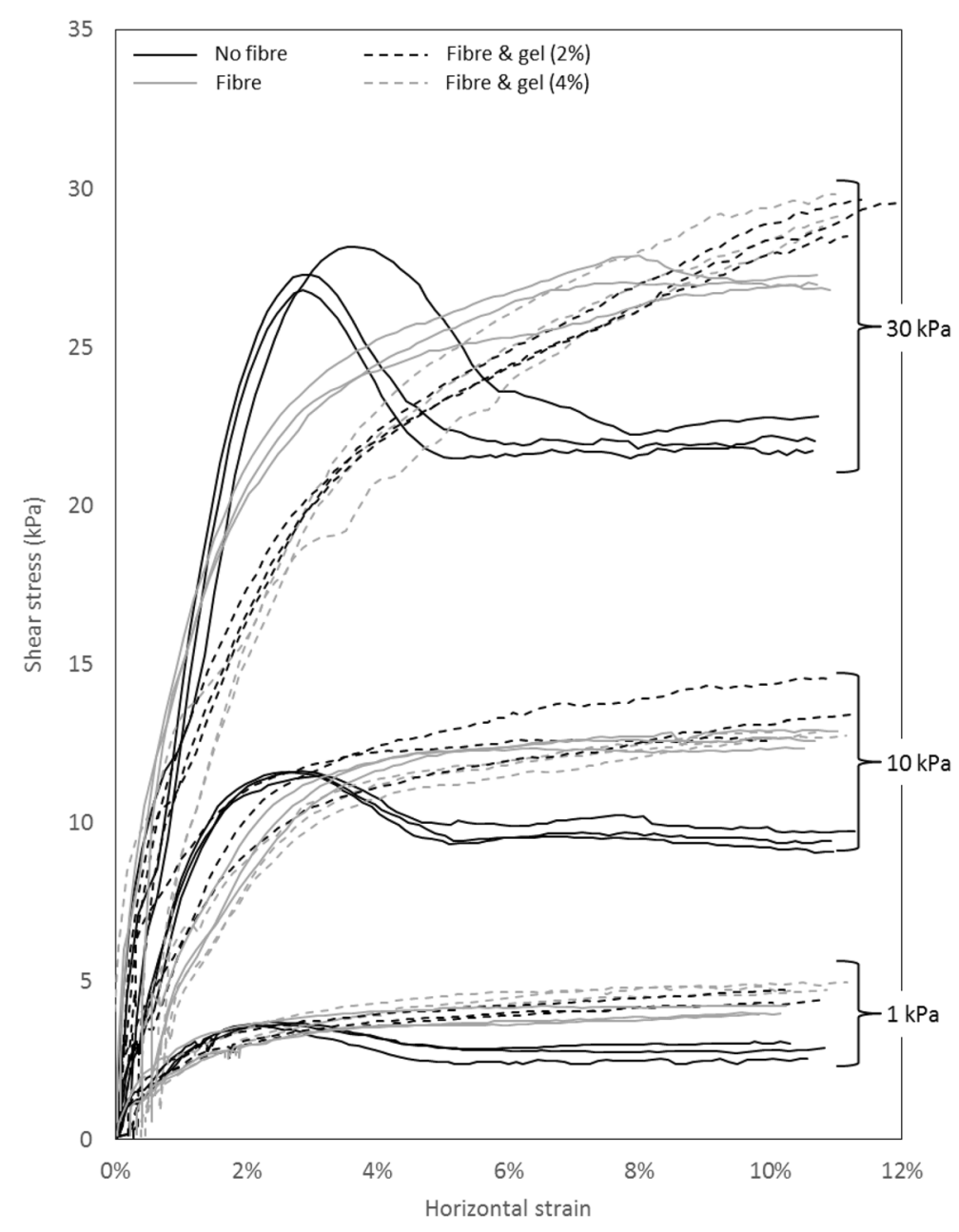

Table 1 Summary of maximum and ultimate shear stresses for tests presented on Figs. 2 and 3

\begin{tabular}{|c|c|c|c|c|c|c|}
\hline \multirow[t]{2}{*}{ Condition } & \multicolumn{2}{|c|}{ Normal stress: $1 \mathrm{kPa}$} & \multicolumn{2}{|c|}{ Normal stress: $10 \mathrm{kPa}$} & \multicolumn{2}{|c|}{ Normal stress: $30 \mathrm{kPa}$} \\
\hline & Maximum & Ultimate & Maximum & Ultimate & Maximum & Ultimate \\
\hline No fibre & $3.639 \pm 0.032^{\mathrm{A} *}$ & $2.798 \pm 0.153^{\mathrm{a}}$ & $11.556 \pm 0.042^{\mathrm{C}_{*}}$ & $9.402 \pm 0.175^{\mathrm{d}}$ & $27.417 \pm 0.399^{\mathrm{F}} *$ & $22.181 \pm 0.313^{\mathrm{g}}$ \\
\hline Fibre $(0.26 \%)$ & $4.093 \pm 0.079^{\mathrm{A}}$ & $4.072 \pm 0.081^{\mathrm{a}}$ & $12.667 \pm 0.153^{\mathrm{CD}}$ & $12.620 \pm 0.164^{\mathrm{e}}$ & $27.315 \pm 0.287^{\mathrm{F}}$ & $27.013 \pm 0.111^{\mathrm{h}}$ \\
\hline Fibre $(0.26 \%)$, gel $(2 \%)$ & $4.481 \pm 0.125^{\mathrm{AB}}$ & $4.448 \pm 0.127^{\mathrm{bc}_{\dagger}}$ & $14.074 \pm 0.329^{\mathrm{E}}$ & $14.026 \pm 0.343^{\mathrm{f}_{\dagger}}$ & $29.232 \pm 0.367^{\mathrm{G}}$ & $29.137 \pm 0.363^{\mathrm{i}} \dagger$ \\
\hline Fibre $(0.26 \%)$, gel $(4 \%)$ & $4.824 \pm 0.065^{\mathrm{AB}}$ & $4.769 \pm 0.072^{\mathrm{bc}_{\dagger}}$ & $12.852 \pm 0.025^{\mathrm{CDE}}$ & $12.798 \pm 0.39^{\mathrm{ef}_{\dagger}}$ & $29.259 \pm 0.303^{\mathrm{G}}$ & $29.063 \pm 0.340^{\mathrm{i}} \dagger$ \\
\hline Fibre $(0.52 \%)$ & $5.398 \pm 0.040^{\mathrm{B}}$ & $5.333 \pm 0.039^{\mathrm{c}}$ & $13.750 \pm 0.105^{\mathrm{DE}}$ & $13.578 \pm 0.048^{\mathrm{ef}}$ & $33.213 \pm 0.545^{\mathrm{H}}$ & $32.319 \pm 0.495^{\mathrm{j}}$ \\
\hline
\end{tabular}

Values presented are means \pm standard error $(n=3)$

Different capital letters indicate differences in the maximum stress among the five applied conditions $(P<0.05)$

Different miniscule letters indicate differences in the ultimate stress among the five applied conditions $(\mathrm{P}<0.05)$

*denotes presence of a clear and repeatable peak in replicate data

$\dagger$ denotes a non-static ultimate stress 

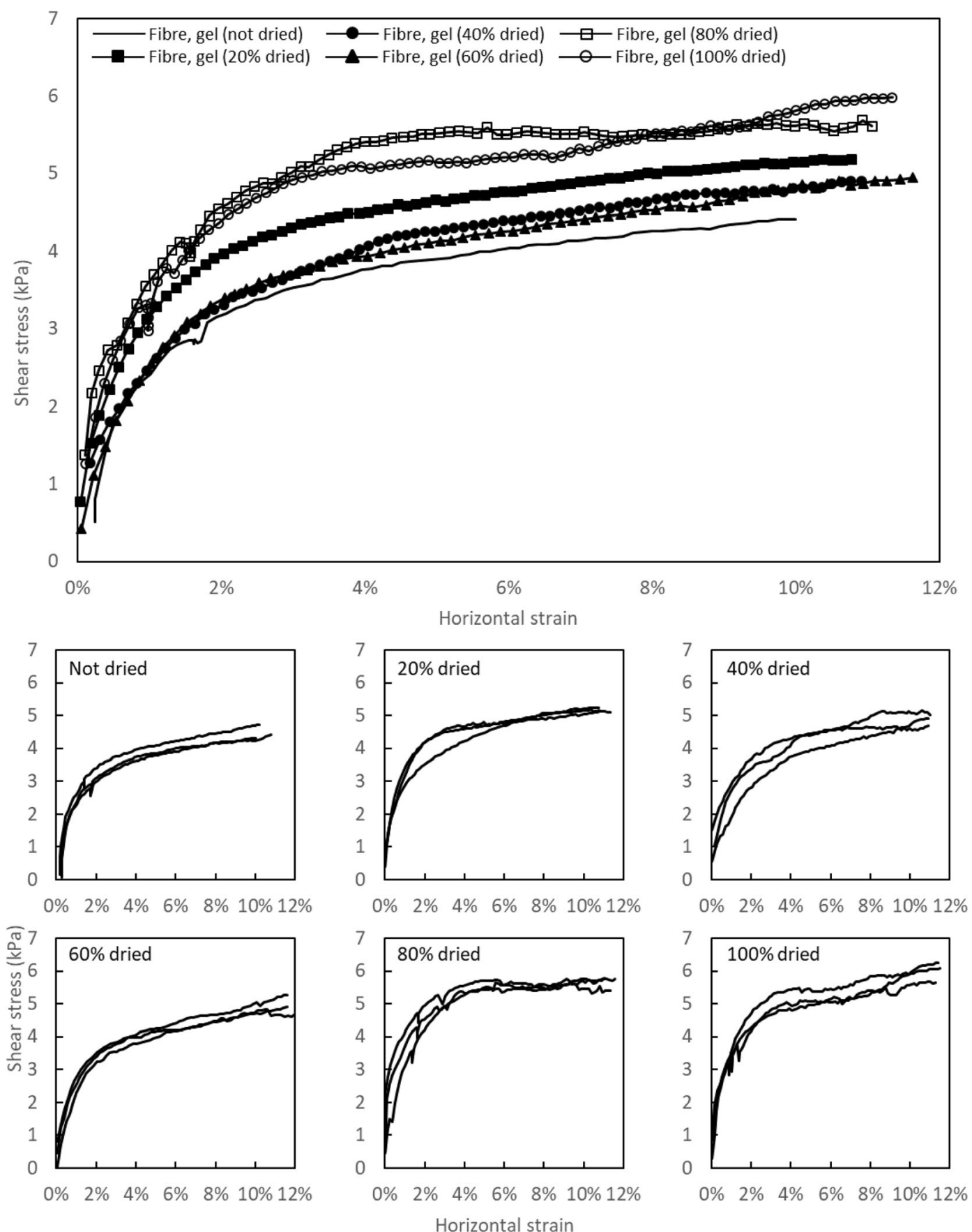

Fig. 4 Impact of drying on shear performance of sand reinforced with $0.26 \%$ branched fibres and biopolymer gel. Main plot: Solid lines represent averaged shear stress values $(n=3)$ for a given level of specimen drying. Minor plots: Each replicate is presented individually

Effect of drying on the shear performance of fibre/gel/ soil composites

Further gel-coated branched fibre-reinforced sand specimens were prepared and dried at room temperature until they had lost $20 \%, 40 \%, 60 \%, 80 \%$ and $100 \%$ of their original moisture before being tested under direct shear at a normal stress of $1 \mathrm{kPa}$ (Fig. 4). Good repeatability between triplicates was observed (minor plots on Fig. 4). With this small amount of fibres tested $(0.26 \%$ 
fibre area ratio, or 12 fibres), the fibre reinforcement on its own led to a loss of brittle behaviour with no clear peak present, but a considerable increase in ultimate strength, as previously shown (Fig. 3). Similar behaviour is observed with fresh and dried gel present with increasing drying typically leading to increasing shear stress for a given strain. Partially dried gel/fibre reinforced soil specimens (20, 40 and 60\% water loss) all had a similar ultimate stress at the end of testing, approximately 10-20\% greater than that with fresh gel on average. The initial response was similar to that with fresh gel for 40 and $60 \%$-dried samples, although with $20 \%$ drying, the shear stress in two of the three specimens climbed to a higher stress before levelling out. With specimens dried to 80 and $100 \%$ water loss, the shear stresses at a given strain were broadly similar, though higher than previously. The $80 \%$-dried specimens exhibited greater variability initially than other specimen groups.

A summary table of ultimate stresses, together with statistical significance information, is presented (Table 2). As described above, ultimate stresses were determined as either the consistent stable stress reached by the end of testing or from an average of the final five stress measurements.

Following the direct shear testing of the dried gelamended specimens discussed above, the sand not associated with fibres was dry-sieved to determine the particle size distribution. Figure 5 clearly demonstrates that partially or fully dried specimens had an increased incidence of particles between 300 and $600 \mu \mathrm{m}$ in size, with a concomitant reduction in particles between 63 and $150 \mu \mathrm{m}$. This suggests that increased aggregation of

Table 2 Summary of ultimate shear stresses for tests presented on Fig. 4

\begin{tabular}{ll}
\hline Condition & Ultimate stress $(\mathrm{kPa})$ \\
\hline Fibre, gel (not dried) & $4.448 \pm 0.127^{\mathrm{a}_{\dagger}}$ \\
Fibre, gel (20\% dried) & $5.178 \pm 0.037^{\mathrm{bc}_{\dagger}}$ \\
Fibre, gel (40\% dried) & $4.876 \pm 0.138^{\mathrm{ab}_{\dagger}}$ \\
Fibre, gel (60\% dried) & $4.909 \pm 0.171^{\mathrm{ab}_{\dagger}}$ \\
Fibre, gel (80\% dried) & $5.622 \pm 0.108^{\mathrm{cd}}$ \\
Fibre, gel (100\% dried) & $5.974 \pm 0.171^{\mathrm{d}_{\dagger}}$ \\
\hline
\end{tabular}

Values presented are means \pm standard error $(n=3)$

Different miniscule letters indicate differences in the ultimate stress among the five applied conditions $(\mathrm{P}<0.05)$

$\uparrow$ denotes a non-static ultimate stress the sand occurs due to drying of the gel in the region of the fibre. Fresh gel did not have a noticeably different distribution to sand alone.

Changes in shear strength over wetting and drying cycles

Figure 6 presents the greatest shear strength recorded in direct shear tests on specimens (normal stress, $1 \mathrm{kPa}$ ) subjected to increasing numbers of wetting and drying cycles. In all specimens consistent ultimate stresses were reached without any significant peaks being observed. Specimens without biopolymer gel or with wetted gel exhibited typical loose sand behaviour (monotonically decreasing stress gradient). Dried specimens with gel typically exhibited a more brittle response, but there was little or no post-yield decrease in stress. It is these consistent maximum stresses that are presented on Fig. 6. Little change in shear performance was observed with fibres present upon initial wetting in the first cycle, although there was a significant $(p<0.05)$ decrease in maximum stress with wetting of sand alone. Upon drying, however, the peak strength increased by a factor of two in specimens amended with fibres and gel. With fibres (no gel), and sand only, an improvement was noted upon drying which was much smaller than with gel, although still significantly higher than the preceding wetted strength $(p<0.05)$. Thereafter, changes in maximum shear stress between wetting and drying cycles were all significant for all treatments. Dried strengths for all three treatments were significantly different from each other at each cycle $(p<0.05)$, whilst there was no such distinction between saturated fibre-reinforced specimens with or without gel (indicating the small effect of saturated gel). Wetted sand specimens were significantly weaker, however.

\section{Discussion}

Using an idealised experimental model of a complex natural system

The idealised fibre/gel/sand composite employed as a root system model is a considerable oversimplification of natural systems. Instead of the simple branched structures used here, root architectures are complex and environment-dependent whilst the root fibres themselves vary in physical (e.g. diameter, depth) and 
Fig. 5 Particle size distribution curves for sand after gel-treated fibres and adhering sand removed

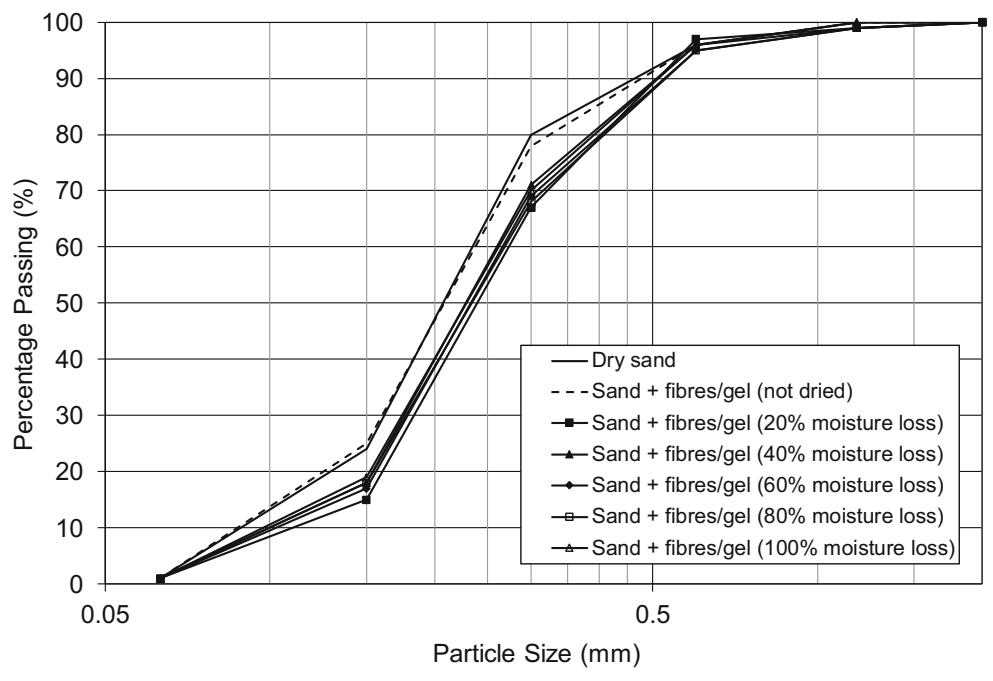

mechanical properties such as stiffness (Liang et al. 2017), presence of hairs (Koebernick et al. 2017) rate of exudation and so on (Huang et al. 2014; Marschner 2012). The exudate itself can vary considerably in its chemistry, which in turn impacts upon the degree of soil stabilisation - different plant exudates can strengthen or weaken soils, which has been correlated with the polysaccharide and organic acid content (Naveed et al. 2017a). Similarly, exudates from different sources associated with soils can positively or negatively affect soil water repellency, with subsequent effects on water transport and suction behaviour (Naveed et al. 2017b). The soil system will differ in terms of soil moisture levels, the presence of other organic matter (e.g. humic acids)

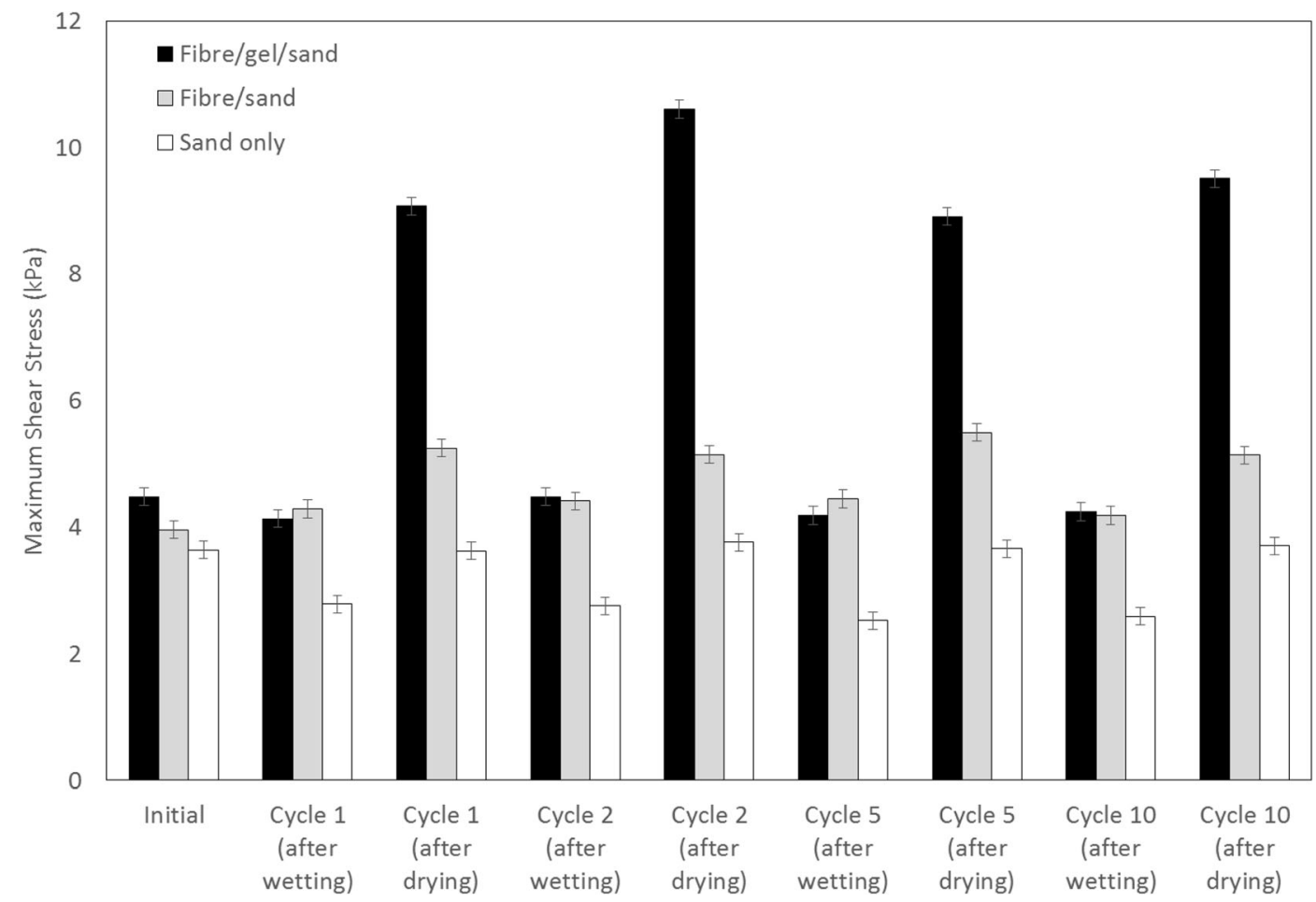

Fig. 6 Maximum shear stress in gel-coated fibre-reinforced sand, fibre reinforced sand and sand only specimens $(1 \mathrm{kPa}$ normal stress, $0.26 \%$ fibre area ratio) subjected to wetting and drying cycles. Error represent the standard error of the mean $(n=3)$ 
and soil grain properties (e.g. size, surface charge, shape). Not only that but many aspects of this system are transient - roots grow or decline, moisture levels vary, biopolymers are degraded et cetera. The idealised system employed here is not designed to mimic these many effects, although roots as fibres are perhaps the most fundamental effect on vegetated soil and they are considered as such in many models of soil reinforcement (Wu 2013). Instead, they offer a basic model upon which the effect of biopolymer, as a model mucilage, can be elucidated whilst minimising confounding effects of other factors. This has allowed us to understand the likely key impacts on the geotechnical behaviour of vegetated soil, whilst knowing that biopolymers can have a measurable effect at such scales may contribute to the design or management of vegetated soils for infrastructure purposes. However, the effect of the soil and plant factors discussed above on the role of biopolymer and the magnitude of its impact on larger scale geotechnical behaviour is an appropriate topic for future work in this area.

Changes to the stress-strain behaviour of sand when fibres were added (Fig. 2) corresponds to the expected behaviour as reported in the literature. The initial, pseudo-elastic stiffness was not significantly affected with fibres present whilst there is substantial improvement of the ultimate stress, as previously observed with physical (Gray and Ohashi 1983; Sadek et al. 2010) and numerical models (Bourrier et al. 2013; Mao et al. 2014). With sufficient fibre content an increased but delayed peak was observed, corresponding to the observations of Gray and Ohashi (1983) and Sadek et al. (2010), whilst the decreased post-peak reduction is explained by the ability of the fibres to provide shear resistance after the soil itself has reached its peak strength (Liang et al. 2017). The presence of gel significantly improved the maximum stress only at $30 \mathrm{kPa}$ normal stress, whereas the impact on ultimate stress was significant at all levels of normal stress. These improvements are typically mobilised at larger strains compared to specimens without gel.

As the behaviour of xanthan gum is considered to be representative of a typical biopolymer in the soil environment, the behaviour observed above is expected to be representative of vegetated soil behaviour (Malarkey et al. 2015; Redmile-Gordon et al. 2014). Despite the mass of biopolymer being small compared to that used for ground improvement purposes by Chang et al.
(Chang et al. 2016, 2017) (0.18 mg dry biopolymer per $g$ sand for $0.26 \%$ fibre area ratio and $2 \%$ gel), and its physical distribution restricted to the zone immediately adjacent to the 'root', it is able to offer a noticeable contribution to the geotechnical performance of this artificially planted soil.

Effect of depth on root/soil interaction enhancement mediated by biopolymers

There are two competing effects of gel, and therefore of natural biopolymers, on sand. The presence of biopolymers in the rhizosphere contributes to mechanical performance and overall increased cohesion of the soil mass through aggregation and bonding of multiple particles around the fibre (Jones et al. 2009; Walker et al. 2003). Any cohesion enhancement would be fixed, and therefore would become less significant with depth as frictional effects increased in importance. We attribute the greatest proportional improvement in shear performance of fibre/ biopolymer-stabilised sand at the lowest normal stress $(1 \mathrm{kPa})$, equivalent to the shallowest depth (Fig. 3), to the cohesive effects of the gel.

At greater depths, where the frictional response of soils increasingly governs mechanical performance, there are lubrication effects that limit the rate of shear strength mobilisation and may contribute to increased densification in regions where biopolymer is present. At the lowest stress (shallowest depth), no effect from lubrication on the rate of shear stress mobilisation was observed. At the highest normal stress $(30 \mathrm{kPa})$, however, gel inclusion led to markedly reduced stress mobilisation with strain, which is suggestive of lubrication. An increased ultimate stress was also observed under these conditions, which is thought to have been caused by increased packing and densification made possible by particle lubrication. The magnitude of the increase was greater than that observed at lower normal stresses and so cannot be attributed solely to increased cohesion. Root growth at depth and in compacted soil is aided by the presence of freshly exuded mucilage which lubricates root caps to facilitate root extension (Iijima et al. 2003; Oleghe et al. 2017), and so a similar effect of freshly prepared gel is not unexpected. However, the decreasing prevalence of biopolymer with distance below the soil surface means that such effects will be less likely to impact upon soil bulk properties. 
Increased strength of biopolymer composites with drying

A soil environment will be subjected to substantial changes in the moisture regime, particularly near the surface where plant roots are located. Fresh plant mucilage is moist and, amongst other things, provides lubrication to allow ease of penetration of the growing root through the soil, as discussed previously. The majority of root length is located in the vadose zone, which is usually only partially saturated with pore water, and so once released into the soil environment the mucilage will be subjected to drying, which will affect the mechanical properties of the gel.

As a polymer gel dries, the individual molecules are increasingly likely to approach and interact with one another, allowing secondary bonds to develop and therefore increasing the viscosity, and resistance to shear, of the gel, in this case bonding the fibres and surrounding sand grains more firmly together. The higher ultimate shear stress observed with partially and fully dried gels (Fig. 4) may be attributed to a more strongly held artificial rhizosheath and increased resistance to motion of this 'column' of sand surrounding the fibres within the wider sand specimen. This is in agreement with the conclusion of Barrere et al. (1986) and Watt et al. (1994) who demonstrated similar drying effects in the rhizosheath.

Although these changes in stress/strain response compared to the fresh gel are relatively modest in themselves, they are statistically significant at higher levels of drying (Table 2) and it should be noted that drying contributes an approximately $30 \%$ increase in ultimate shear strength ( 80 and $100 \%$ dried) at the end of testing despite there being only a very small mass of gel present in a small number of isolated fibre locations. Also, when comparing this to the impact of fibres alone at the same low normal stress (Fig. 3 and Table 1), it is observed that the contribution of dried gel around fibres to the soil performance (45\% increase in maximum strength compared to fibres [0.26\%] alone) is greater than the effect of the fibres themselves (approximately 12\% increase in highest stress mobilised compared to sand alone). It may therefore be expected that plant mucilage will provide a sizeable contribution to the geotechnical performance of shallow rooted soils upon drying. It is expected, however, that this is a more important effect at very low normal stresses observed in shallow soils, as with increasing normal stress the increasing role of friction between grains and fibres will overcome the impact of the gel, dried or not.

The similarity between the particle size distributions at different levels of drying (Fig. 5) is likely to be because the amount of gel present in each test was similar, and so the extent of the gel's influence will remain the same once a particular drying threshold is reached. With fresh gel, the inter-grain bonding may not have been sufficient for the aggregate to act as a single unit. Increased aggregation can be attributed to the presence of vegetation, through the release of exudates, enhanced microbial activities and greater levels of soil organic carbon; this aggregation has been found to be correlated with increased cohesion but with no apparent effect on angle of friction (Fattet et al. 2011). The presence of larger aggregates may therefore be at least a partial cause of the observed changes in shear strength in the presence of an artificial plant mucilage through greater interlocking. As the shear strength appears to increase with degree of drying but the particle size distribution does not change, there is likely to be an additional cause, such as stronger intra-aggregate and sand-fibre cementation.

Cyclic shear behaviour during wetting and drying cycles

It was shown above that drying of the gel-coated fibre reinforced specimens led to an increase in sand aggregation and an increase in ultimate shear strength. However, subsequent rewetting of the gel may cause it to swell and lose any previously gained shear strength whilst over multiple cycles of wetting and drying the gel performance may deteriorate. In the natural environment, drying and wetting cycles not only affect the plant growth, but also influence the mineralization, aggregation and structure in the soil (Six et al. 2000). Previous tests showed periodic drying and wetting cycles increased the soil aggregate strength. Czarnes et al. (2000) suggested secretion of root biopolymers combined with wetting and drying cycles stabilize soil structure by increasing the strength of bonds between particles and buffering the destructive features of rapid wetting rates.

The considerable improvements in maximum mobilisable shear strength observed in gel-amended specimens following drying cycles (Fig. 6) are much greater than those observed simply through drying alone (Fig. 4). The drying process in the former was at an elevated temperature $\left(40{ }^{\circ} \mathrm{C}\right.$ as opposed to room 
temperature), which may have caused a difference in the final polymer structure, but the ultimate state should be similar. However, a major difference between the two is the preceding wetting cycle present in the former case. Originally, fibres coated in gel were simply placed in the sand, and gel bonding to sand simply through contact between the two would be limited. Xanthan gum can be dispersed in water, as can the biopolymers that make up root mucilage, and so it is suggested that wetting disrupted the original gel structure, enhancing the ability of polymer molecules to adhere to the surrounding grain surfaces and increasing bond strength between fibre and sand. Upon drying, this has the effect of widening the zone of influence of the biopolymer, increasing the diameter of the fibre-associated sand region (and its resilience to shear), and so increasing the resistance to motion of the fibre and attached sand grains within the specimen, consequently increasing the shear resistance of the fibre/gel/sand composite.

The complete loss of additional strength due to gel following each rewetting stage may be attributed to rapid resaturation of the thin gel films around the surface of each fibre and loss of polymer molecule interactions. Gains and losses in maximum mobilisable shear strength appear consistently over the ten cycles tested, with no apparent deterioration in performance, unlike that seen with high levels of gel only (Chang et al. 2017) where the maximum peak strength upon drying decreased with number of cycles, attributed to gradual breakdown of the gellan gum structure bonding sand grains upon wetting. No such breakdown was observed here, although given the ability of xanthan gum to slowly dissolve it is expected that deterioration would gradually occur as the biopolymer molecules gradually dispersed. For soils with consistent levels of biopolymer present, maintained through a degree of turnover and so production of fresh biopolymer as older material breaks down, the effect on mechanical properties due to the presence of biopolymer will be consistent.

\section{Conclusions}

The presence of biopolymers such as plant mucilage at the root/soil interface contributes to the ability of vegetation to stabilise and strengthen surface soils. Using an analogue of root and mucilage in sand, improvements in shear strength were observed due to the mucilage gel particularly at shallower depths, whilst increasing effects of lubrication were seen at depth as frictional behaviour began to dominate. Drying of the gel caused further increases in shear strength of up to $30 \%$. At shallow depths, the enhancement provided by the gel was comparable to that provided by the root fibres. Wetting and drying cycles demonstrated substantial and consistent variation in the contribution of gel to shear strength between the dry and wetted state, with the former exhibiting a $100 \%$ increase in strength over the latter. The potential for mucilage to enhance soil stabilisation even in relatively coarse-grained soil has been demonstrated but is dependent on the soil moisture regime. Although surface soils are likely to be unsaturated for the majority of the time, and therefore may benefit from biopolymer strengthening, this particular component of soil structure is susceptible to losses in strength upon increases of water content in the soil. Changes in strength of vegetated soils upon wetting may therefore arise not only due to changes in suction but also to the ability of biopolymers to sustain loading at different levels of moisture, with potential consequences in situations such as the stability of vegetated slopes subject to rainfall. However, if the observed effects are confirmed at a larger scale then schemes to optimise the effects of plant-associated biopolymers (e.g. moisture control, plant selection) may be incorporated into the management and design of vegetated soil infrastructure.

Acknowledgements This work is supported in part by the scholarship from China Scholarship Council (CSC) under the Grant CSC No. 201606410015.

Open Access This article is distributed under the terms of the Creative Commons Attribution 4.0 International License (http:// creativecommons.org/licenses/by/4.0/), which permits unrestricted use, distribution, and reproduction in any medium, provided you give appropriate credit to the original author(s) and the source, provide a link to the Creative Commons license, and indicate if changes were made.

\section{References}

Ahmed A, Hussain I (2010) Use of biological approach for ground improvement. Proc Inst Civ Eng Ground Improv 163:135140

Akhtar J, Galloway AF, Nikolopoulos G, Field KJ, Knox P (2018) A quantitative method for the high throughput screening for the soil adhesion properties of plant and microbial polysaccharides and exudates. Plant Soil 428:57-65. https://oi.org/10.1007/s11104-018-3670-1 
Albalasmeh AA, Ghezzehei TA (2014) Interplay between soil drying and root exudation in rhizosheath development. Plant Soil 374:739-751. https://doi.org/10.1007/s11104013-1910-y

Banagan B, Wertheim B, Roth M, Caslake L (2010) Microbial strengthening of loose sand. Lett Appl Microbiol 51:138-142

Barrere G, Barber C, Daniels M (1986) Molecular cloning of genes involved in the production of the extracellular polysaccharide xanthan by Xanthomonas campestris pv. campestris. Int J Biol Macromol 8:372-374

Benard P, Zarebanadkouki M, Hedwig C, Holz M, Ahmed MA, Carminati A (2018) Pore-scale distribution of mucilage affecting water repellency in the rhizosphere. Vadose Zone J 17. UNSP 170013 https://doi.org/10.2136/vzj2017.01.0013

Bischetti GB, Chiaradia EA, Simonato T, Speziali B, Vitali B, Vullo P, Zocco A (2005) Root strength and root area ratio of forest species in Lombardy (Northern Italy). Plant Soil 278: 11-22. https://doi.org/10.1007/s11104-005-0605-4

Bourrier F, Kneib F, Chareyre B, Fourcaud T (2013) Discrete modeling of granular soils reinforcement by plant roots. Ecol Eng 61:646-657

Carminati A, Moradi AB, Vetterlein D, Vontobel P, Lehmann E, Weller U, Vogel HJ, Oswald SE (2010) Dynamics of soil water content in the rhizosphere. Plant Soil 332:163-176

Carminati A, Zarebanadkouki M, Kroener E, Ahmed MA, Holz M (2016) Biophysical rhizosphere processes affecting root water uptake. Ann Bot 118:mcw113

Cerato AB, Lutenegger AJ (2006) Specimen size and scale effects of direct shear box tests of sands. Geotech Test J 29:507-516

Chang I, Im J, Cho G-C (2016) Geotechnical engineering behaviors of gellan gum biopolymer treated sand. Can Geotech J 53:1658-1670

Chang I, Im J, Lee S-W, Cho G-C (2017) Strength durability of gellan gum biopolymer-treated Korean sand with cyclic wetting and drying. Constr Build Mater 143:210-221

Czarnes S, Hallett P, Bengough A, Young I (2000) Root-and microbial-derived mucilages affect soil structure and water transport. Eur J Soil Sci 51:435-443

Danjon F, Reubens B (2008) Assessing and analyzing 3D architecture of woody root systems, a review of methods and applications in tree and soil stability, resource acquisition and allocation. Plant Soil 303:1-34

De Baets S, Poesen J, Reubens B, Wemans K, De Baerdemaeker J, Muys B (2008) Root tensile strength and root distribution of typical Mediterranean plant species and their contribution to soil shear strength. Plant Soil 305:207-226

DeJong JT, Mortensen BM, Martinez BC, Nelson DC (2010) Biomediated soil improvement. Ecol Eng 36:197-210

Di Marsico A, Scrano L, Labella R, Lanzotti V, Rossi R, Cox L, Perniola M, Amato M (2018) Mucilage from fruits/seeds of chia (Salvia hispanica L.) improves soil aggregate stability. Plant Soil:1-13

Fattet M, Fu Y, Ghestem M, Ma W, Foulonneau M, Nespoulous J, Le Bissonnais Y, Stokes A (2011) Effects of vegetation type on soil resistance to erosion: relationship between aggregate stability and shear strength. Catena 87:60-69

Gray DH, Ohashi H (1983) Mechanics of fiber reinforcement in sand. J Geotech Eng 109:335-353

Gregory P (2006) Roots, rhizosphere and soil: the route to a better understanding of soil science? Eur J Soil Sci 57:2-12
Hall-Stoodley L, Costerton JW, Stoodley P (2004) Bacterial biofilms: from the natural environment to infectious diseases. Nat Rev Microbiol 2:95-108. https://doi.org/10.1038 /nrmicro821

Hejazi SM, Sheikhzadeh M, Abtahi SM, Zadhoush A (2012) A simple review of soil reinforcement by using natural and synthetic fibers. Constr Build Mater 30:100-116

Hinsinger P, Bengough AG, Vetterlein D, Young IM (2009) Rhizosphere: biophysics, biogeochemistry and ecological relevance. Plant Soil 321:117-152

Huang X-F, Chaparro JM, Reardon KF, Zhang R, Shen Q, Vivanco JM (2014) Rhizosphere interactions: root exudates, microbes, and microbial communities. Botany 92:267-275

Iijima M, Higuchi T, Barlow PW, Bengough AG (2003) Root cap removal increases root penetration resistance in maize (Zea mays L.). J Exp Bot 54:2105-2109

Jewell RA, Wroth CP (1987) Direct shear tests on reinforced sand. Geotechnique 37:53-68. https://doi. org/10.1680/geot.1987.37.1.53

Jones DL, Nguyen C, Finlay RD (2009) Carbon flow in the rhizosphere: carbon trading at the soil-root interface. Plant Soil 321:5-33

Kim J, Kim Y, Jeong S, Hong M (2017) Rainfall-induced landslides by deficit field matric suction in unsaturated soil slopes. Environ Earth Sci 76. ARTN 808. https://doi. org/10.1007/s12665-017-7127-2

Koebernick N, Daly KR, Keyes SD, George TS, Brown LK, Raffan AC, Cooper L, Naveed M, Bengough AG, Sinclair I, Hallett PD, Roose T (2017) High-resolution synchrotron imaging shows that root hairs influence rhizosphere soil structure formation. New Phytol 216:124 135. https://doi.org/10.1111/nph.14705

Kroener E, Zarebanadkouki M, Kaestner A, Carminati A (2014) Nonequilibrium water dynamics in the rhizosphere: how mucilage affects water flow in soils. Water Resour Res 50: 6479-6495. https://doi.org/10.1002/2013wr014756

Liang T, Knappett JA, Bengough AG, Ke YX (2017) Small-scale modelling of plant root systems using $3 \mathrm{D}$ printing, with applications to investigate the role of vegetation on earthquake-induced landslides. Landslides 14:1747-1765. https://doi.org/10.1007/s10346-017-0802-2

Malarkey J, Baas JH, Hope JA, Aspden RJ, Parsons DR, Peakall J, Paterson DM, Schindler RJ, Ye L, Lichtman ID (2015) The pervasive role of biological cohesion in bedform development. Nat Commun 6:6257

Mao Z, Yang M, Bourrier F, Fourcaud T (2014) Evaluation of root reinforcement models using numerical modelling approaches. Plant Soil 381:249-270

Marschner P (2012) Rhizosphere biology. Marschner's mineral nutrition of higher plants, Third edn. Elsevier

Naveed M, Brown L, Raffan A, George TS, Bengough AG, Roose T, Sinclair I, Koebernick N, Cooper L, Hackett CA (2017a) Plant exudates may stabilize or weaken soil depending on species, origin and time. Eur J Soil Sci 68:806-816

Naveed M, Brown LK, Raffan AC, George TS, Bengough AG, Roose T, Sinclair I, Koebernick N, Cooper L, Hallett PD (2017b) Rhizosphere-scale quantification of hydraulic and mechanical properties of soil impacted by root and seed exudates. Vadose Zone J 17: 0- 
Ni JJ, Leung AK, Ng CWW (2018) Modelling soil suction changes due to mixed species planting. Ecol Eng 117:1-17. https://doi.org/10.1016/j.ecoleng.2018.02.023

Oleghe E, Naveed M, Baggs EM, Hallett PD (2017) Plant exudates improve the mechanical conditions for root penetration through compacted soils. Plant Soil 421:19-30. https://doi.org/10.1007/s11104-017-3424-5

Peng X, Hallett PD, Zhang B, Horn R (2011) Physical response of rigid and non-rigid soils to analogues of biological exudates. Eur J Soil Sci 62:676-684. https://doi.org/10.1111/j.13652389.2011.01383.x

Redmile-Gordon M, Brookes P, Evershed R, Goulding K, Hirsch $P$ (2014) Measuring the soil-microbial interface: extraction of extracellular polymeric substances (EPS) from soil biofilms. Soil Biol Biochem 72:163-171

Sadek S, Najjar SS, Freiha F (2010) Shear strength of fiberreinforced sands. J Geotech Geoenviron 136:490-499

Six J, Elliott E, Paustian K (2000) Soil macroaggregate turnover and microaggregate formation: a mechanism for $\mathrm{C}$ sequestration under no-tillage agriculture. Soil Biol Biochem 32: 2099-2103

Stokes A, Atger C, Bengough AG, Fourcaud T, Sidle RC (2009) Desirable plant root traits for protecting natural and engineered slopes against landslides. Plant Soil 324:1-30
Vanapalli S, Fredlund D, Pufahl D, Clifton A (1996) Model for the prediction of shear strength with respect to soil suction. Can Geotech J 33:379-392

Walker TS, Bais HP, Grotewold E, Vivanco JM (2003) Root exudation and rhizosphere biology. Plant Physiol 132:44-51

Watt M, McCully ME, Canny MJ (1994) Formation and stabilization of rhizosheaths of Zea mays L.(effect of soil water content). Plant Physiol 106:179-186

Whalley WR, Riseley B, Leeds-Harrison PB, Bird NR, Leech PK, Adderley WP (2005) Structural differences between bulk and rhizosphere soil. Eur J Soil Sci 56:353-360

Wu TH (2013) Root reinforcement of soil: review of analytical models, test results, and applications to design. Can Geotech J 50:259-274

Zickenrott IM, Woche SK, Bachmann J, Ahmed MA, Vetterlein D (2016) An efficient method for the collection of root mucilage from different plant species - a case study on the effect of mucilage on soil water repellency. J Plant Nutr Soil Sci 179:294-302

Publisher's note Springer Nature remains neutral with regard to jurisdictional claims in published maps and institutional affiliations. 